\title{
Effect of adjunctive corticosteroid on 28-day mortality in neutropenic patients with septic shock
}

\author{
Jieun Kang ${ }^{1}$ - Minkyu Han ${ }^{2}$ - Sang-Bum Hong ${ }^{1} \cdot{\text { Chae-Man } \text { Lim }^{1} \cdot \text { Younsuck Koh }}^{1} \cdot$ Jin Won Huh ${ }^{1}$ (D)
}

Received: 7 April 2019 / Accepted: 14 August 2019 / Published online: 20 August 2019

(C) Springer-Verlag GmbH Germany, part of Springer Nature 2019

\begin{abstract}
The role of adjunctive corticosteroid in septic shock remains debatable, and its role has not been assessed in neutropenic patients. We evaluated whether hydrocortisone reduces 28-day mortality in neutropenic patients with septic shock. We conducted a retrospective cohort study between January 2012 and May 2017 at a tertiary care center in South Korea. Patients who developed septic shock treated with at least one vasopressor and whose absolute neutrophil count was $<1000$ cells $/ \mu \mathrm{L}$ were included. Patients were classified into a steroid and a no-steroid group. The primary outcome of the study was 28-day mortality. Propensity score matching was used to adjust baseline characteristics and disease severity between the groups. Of the 287 patients analyzed, 189 were classified in the no-steroid group and 98 in the steroid group. Fifty propensity score-matched pairs were compared for the study outcomes. We found no significant difference in 28 -day mortality between patients treated with and without steroid after propensity score matching $(38.0 \%$ and $42.0 \%$, respectively; $p=0.838)$. Incidences of pneumonia and gastrointestinal bleeding were more frequent in the steroid group, but it was not statistically significant after matching. In conclusion, adjunctive hydrocortisone was not associated with reduced 28-day mortality in neutropenic patients with septic shock.
\end{abstract}

Keywords Corticosteroids $\cdot$ Neutropenia $\cdot$ Sepsis $\cdot$ Septic shock

\author{
Abbreviations \\ G-CSF Granulocyte colony-stimulating factor \\ ICU Intensive care unit \\ PS Propensity score \\ SOFA Sequential organ failure assessment
}

\section{Introduction}

Although adjunctive corticosteroid is widely used in patients with septic shock who are poor responders to fluid

Electronic supplementary material The online version of this article (https://doi.org/10.1007/s00277-019-03785-w) contains supplementary material, which is available to authorized users.

Jin Won Huh

jwhuh@amc.seoul.kr

1 Department of Pulmonary and Critical Care Medicine, Asan Medical Center, University of Ulsan College of Medicine, 88 Olympic-ro 43-gil, Songpa-gu, Seoul 05505, South Korea

2 Department of Clinical Epidemiology and Biostatistics, Asan Medical Center, Seoul, South Korea resuscitation and vasopressor treatment, debates still remain for its efficacy [1-4]. Two randomized controlled trials revealed conflicting results for the efficacy of lowdose corticosteroid in patients with septic shock. In 2002, Annane et al. demonstrated that low doses of hydrocortisone and fludrocortisone reduced mortality in patients with septic shock and relative adrenal insufficiency [5]. In contrast, hydrocortisone did not improve survival in patients with septic shock regardless of response to corticotropin in the 2008 CORTICUS trial [6]. Despite conflicting results, current guidelines recommend the use of hydrocortisone when hemodynamic stability is not attained [7].

Recently, Venkatesh et al. conducted a large randomized controlled trial (ADRENAL trial) in which patients requiring mechanical ventilation were randomly categorized into either a hydrocortisone or placebo group [8]. They reported no difference in 90-day mortality between the groups, although the hydrocortisone group achieved comparatively faster shock reversal. Conversely, according to another recent study by Annane et al. (APROCCHSS), patients treated with hydrocortisone plus fludrocortisone had lower 90-day all-cause mortality [9]. The ongoing debate on the efficacy of corticosteroid in 
septic shock renders it difficult to make a decision regarding steroid use in patients with a high risk of superinfection.

Managing septic shock is more complicated in neutropenic patients as they are at an increased risk for bacterial infection and subsequent septic shock [10], with a high mortality rate [11]. Although hydrocortisone use is recommended for hemodynamic instability according to the current guidelines, it is burdensome in neutropenic patients; it may cause profound immunosuppression in patients whose immune systems are already suppressed, leading to poor control of the primary infection or exposing vulnerable patients to secondary infections. To our knowledge, no previous study has evaluated the role of hydrocortisone specifically for neutropenic patients with septic shock. Thus, we aimed to evaluate whether adjunctive hydrocortisone reduces 28-day mortality in neutropenic patients with septic shock.

\section{Methods}

\section{Study design and patients}

This was a retrospective study conducted at Asan Medical Center, a 2700-bed tertiary care center in Seoul, South Korea. In our hospital, a rapid response team is in charge of a system that monitors the laboratory results and vital signs of every adult patient in the general ward on a 24-h basis; this system keeps records of patients who were screened for sepsis (sepsis cohort). We retrospectively reviewed the electronic medical records of the patients in this sepsis cohort between January 2012 and May 2017. Inclusion criteria were (i) patients aged $\geq 18$ years who had a documented infection or strong clinical suspicion of infection, (ii) patients treated for septic shock with at least one vasopressor, and (iii) patients whose absolute neutrophil count was $<1000 / \mu \mathrm{L}$ at the time of vasopressor initiation. Patients were excluded if there was recovery of neutropenia in $<24 \mathrm{~h}$ without granulocyte colony-stimulating factor (G-CSF) treatment, because we assumed that patients with rapid recovery of neutropenia are different in immunity or comorbidities, and inappropriate for the assessment of the hydrocortisone effect in neutropenic status. Patients who died within $24 \mathrm{~h}$ were also excluded because the time from hydrocortisone administration to death was too short to assess the hydrocortisone effect. According to a protocol in our hospital, hydrocortisone is considered when high-dose norepinephrine and/or vasopressin is required; thus, patients who were considered to have received hydrocortisone too late (i.e., hydrocortisone administration after epinephrine infusion is started) were also excluded.

The study protocol was approved by the institutional review board of Asan Medical Center (No. 2018-0206), and the need for informed consent was waived due to the retrospective nature of the study.

\section{Data collection and definitions}

Baseline demographic and clinical characteristics obtained from the electronic medical record included age, sex, body mass index, underlying disease, cause of neutropenia, cause of septic shock, laboratory data, severity of illness (sequential organ failure assessment [SOFA] score) [12], presence of bacteremia or fungemia at the time of shock, requirement and duration of mechanical ventilation, dose and duration of vasopressor use, duration and recovery of neutropenia, and use of hydrocortisone.

Septic shock was defined as sepsis with persisting hypotension requiring vasopressor treatment to maintain a mean arterial pressure of $\geq 65 \mathrm{mmHg}$ and having a serum lactate level $>2 \mathrm{mmol} / \mathrm{L}$ despite adequate volume resuscitation [13]. The index date was defined as the date of septic shock development. The time to shock resolution was defined as the duration of vasopressor use from the index date until discontinuation. If a vasopressor was re-administered within $12 \mathrm{~h}$ of stopping drug administration, it was considered to be continued use. Recovery of neutropenia was defined as absolute neutrophil count of $\geq 1000 / \mu \mathrm{L}$ for $\geq 48 \mathrm{~h}$.

\section{Hemodynamic management of septic shock}

Initially, fluid resuscitation with crystalloid solution was administered to patients with septic shock in accordance with the Surviving Sepsis guidelines [7, 14, 15]. If the shock did not resolve, vasopressor treatment was initiated, of which norepinephrine was the preferred initial choice. If a patient remained hypotensive with norepinephrine, vasopressin followed by epinephrine was considered. The decision whether to initiate hydrocortisone was at the treating physician's discretion and was based on the patient's condition. If used, hydrocortisone was initiated when hemodynamic stability was not restored even with high-dose norepinephrine or vasopressin administration; however, the time to hydrocortisone initiation varied with each case as it was determined by the treating physician. Intravenous hydrocortisone was administered at $10 \mathrm{mg} / \mathrm{h}$.

\section{Study outcomes}

Patients were classified as the steroid group and the no-steroid group on the basis of their use of hydrocortisone for septic shock. Patients who had been receiving corticosteroid for the underlying disease before shock continued to receive steroid during the septic shock management; therefore, they were included in the steroid group. The primary outcome of the study was 28-day mortality. The secondary outcomes included duration of stay in the intensive care unit (ICU) and hospital, time to resolution of shock, duration of mechanical ventilation, and incidence rates of superinfection and gastrointestinal bleeding. Superinfection was defined as a newly developed 
infection during a course of the treatment, determined based on chest X-ray findings, microbiologic results, and/or changes in antibiotics.

\section{Statistical analysis}

Continuous variables are presented as mean \pm standard deviation, and categorical variables are presented as numbers and percentages. Chi-square or Fisher's exact test was used to compare categorical variables, and Student's $t$ test or Mann-Whitney $U$ test was used for continuous variables, as appropriate.

In general, hydrocortisone was administered to patients in whom high-dose norepinephrine and/or vasopressin was required to maintain adequate blood pressure; thus, patients who received hydrocortisone had higher SOFA scores and additional vasopressor requirements, which suggests a discrepancy in baseline disease severity between patients who received and did not receive hydrocortisone. A propensity score (PS) analysis was performed to account for the difference in baseline characteristics and disease severity between groups. The propensity score--matched pairs were created by matching the patients who received and who did not receive hydrocortisone using calipers of width equal to 0.1 of the standard deviation of the logit of the propensity score. All statistics were performed using R software version 3.5.1 (The R Foundation for Statistical Computing, Vienna, Austria).

\section{Results}

\section{Clinical characteristics of patients}

Between January 2012 and May 2017, 1596 patients were identified with the diagnosis of septic shock from the sepsis cohort in our institution. Among these patients, 1214 were non-neutropenic (absolute neutrophil count of $\geq 1000$ ) and 46 did not receive any vasopressor treatment; these patients were excluded from analysis. Ten patients who recovered from neutropenia within $24 \mathrm{~h}$ without administration of GCSF, 22 patients who died within $24 \mathrm{~h}$, and 17 who received hydrocortisone too late were also excluded. Of a total of 287 patients remaining for analysis, 189 did not receive adjunctive hydrocortisone (no-steroid group) and 98 received hydrocortisone (steroid group) (Fig. 1).

Baseline characteristics of the study patients are presented in Table 1. Prior to PS matching, mean ages were $53.5 \pm 16.0$ and $57.2 \pm 12.3$ years in the no-steroid and steroid group, respectively. Male patients were predominant in both groups. The most common underlying disease was acute leukemia $\mathbf{4} 4.6 \%$ and $36.7 \%$ in the no-steroid and steroid group, respectively). The most common cause of neutropenia was chemotherapy $(79.4 \%$ and $75.5 \%$ in the no-steroid and steroid group, respectively), with the second most common cause being hematologic malignancy in both groups. The mean SOFA score was significantly higher in the steroid than in the nosteroid group $(10.6 \pm 2.9$ and $9.0 \pm 3.0$, respectively; $p<0.001)$. Significantly more patients in the steroid group were treated with vasopressin and epinephrine (Table 1) $(p<0.001)$. The number of patients who were admitted or transferred to the ICU and who required mechanical ventilation was significantly higher in the steroid group.

Because baseline clinical characteristics differed between the no-steroid and steroid group, PS matching was applied to adjust baseline discrepancies between the groups. Fifty patients in each group were matched, and there was no significant difference in baseline characteristics between groups, except for the number of patients who were admitted to ICU and those who required mechanical ventilation. Requirements of vasopressor and mean SOFA scores were similar after PS matching between the groups as shown in Table 1 .

\section{Study outcomes}

Study outcomes are presented in Table 2. Death within 28 days occurred in 55 and 47 patients in the no-steroid and steroid group, respectively. Although 28-day mortality was significantly higher in the steroid versus no-steroid group $(48.0 \%$ and $29.1 \%$, respectively; $p<0.001)$ prior to PS matching, there was no significant difference after PS matching $(42.0 \%$ and $38.0 \% ; p=0.838$ ). Durations of ICU and hospital stay were not significantly different between the groups before and after PS matching. Time to shock resolution and length of mechanical ventilation were also similar between the nosteroid and steroid group after matching.

\section{Adverse events}

We investigated the incidence rates of superinfection, including pneumonia, bacteremia/fungemia, and gastrointestinal bleeding within 28 days from the index date (Table 3 ). Patients in the steroid group experienced significantly more pneumonia $(p<0.001)$, which was numerically higher after PS matching $(10.0 \%$ vs. $18.0 \%, p=0.289)$. Occurrence of bacteremia or fungemia was similar between groups. When propensity score was matched, gastrointestinal bleeding was found in four patients treated with steroid whereas none occurred in the no-steroid group.

\section{Subgroup analysis for patients with absolute neutrophil count $<\mathbf{5 0 0}$ cells $/ \mu \mathrm{L}$}

Patients with absolute neutrophil count $<500$ cells $/ \mu L$ were selected for a subgroup analysis, representing a more profound immunosuppression state. A total of 118 patients were found; among them, 76 patients received hydrocortisone and 42 patients did not. To adjust baseline differences, 27 patients in each group 
Fig. 1 Study flow

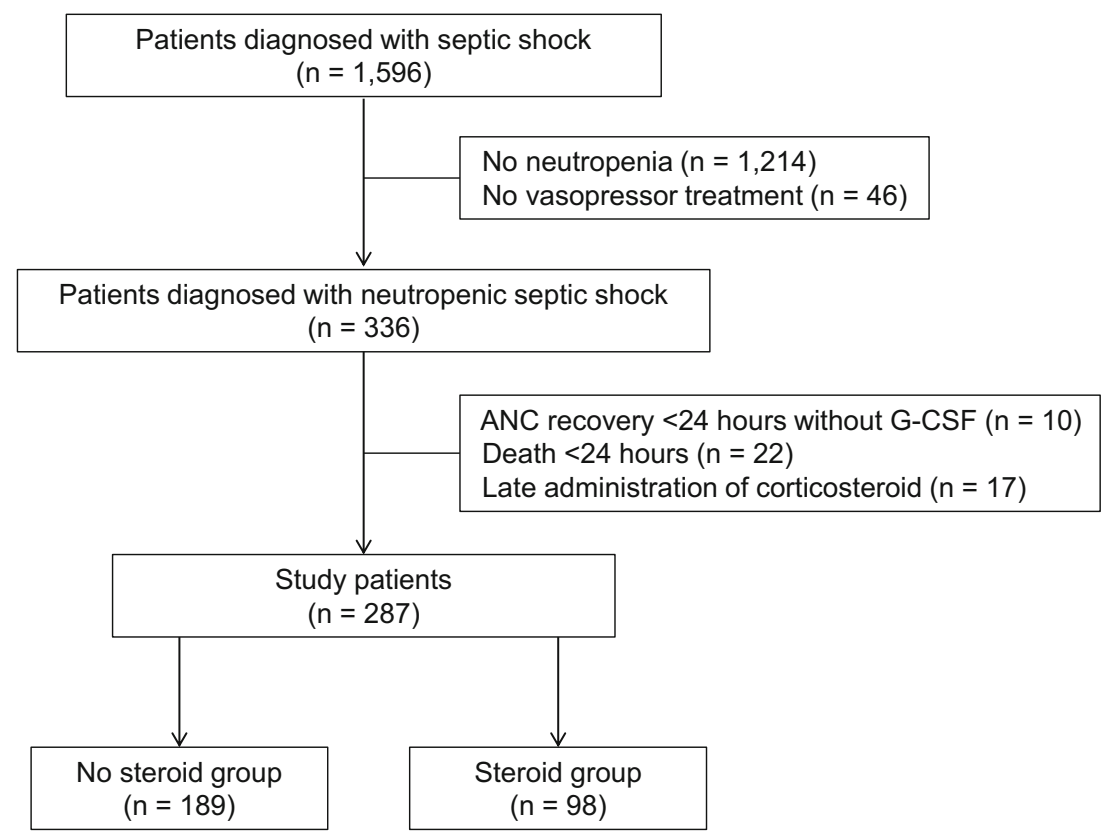

were matched as shown in Table S1 in Supplementary Data. There were no significant differences in 28-day mortality, durations of ICU and hospital stay, time to shock resolution, and length of mechanical ventilation between the two groups (Table S2). Adverse events were not significantly different between the groups as shown in Table S3.

\section{Discussion}

To the best of our knowledge, this is the first study to evaluate the role of adjunctive hydrocortisone specifically in neutropenic patients with septic shock. According to our results, hydrocortisone was not associated with improved 28-day mortality after PS matching. Moreover, time to shock resolution was not significantly different. Incidence rates of adverse events including superimposed pneumonia and gastrointestinal bleeding were more frequent in patients who received hydrocortisone treatment, although statistical significance was not detected after PS matching. The results were similar with patients whose absolute neutrophil count $<500$ cells $/ \mu \mathrm{L}$.

The most important management strategy for septic shock is to control the primary infection; therefore, intact immunity of the affected patients is critical. Because neutrophils are known to play an important role as first responder cells to bacterial or fungal pathogens [16], neutropenic patients have a deficiency in innate immune responses to invading microorganisms [17]. Moreover, neutropenic patients not only are susceptible to opportunistic infections but also are often complicated by secondary infection during their clinical course. As in our analysis, the role of hydrocortisone for septic shock should be assessed separately in neutropenic patients considering the differences between neutropenic and nonneutropenic patients.

Controversy remains with the role of corticosteroid in the management of septic shock. Annane et al. have shown a mortality benefit with the combination of hydrocortisone and fludrocortisone in their clinical trials $[5,9,18]$; however, it is uncertain if the positive result was driven by the addition of fludrocortisone or other factors. One pharmacokinetic study demonstrated that a single dose of fludrocortisone showed undetectable plasma concentration in approximately onethird of patients with septic shock and the half-life was very short [19]. Therefore, the specific role of fludrocortisone is still uncertain and remains as a subject for future studies. In addition, the septic shock management protocol used in our study did not include fludrocortisone and none of the study patients received fludrocortisone. Thus, whether the benefit of hydrocortisone and fludrocortisone in combination can be reproduced in neutropenic patients is unknown. Further studies are warranted to address this issue.

Interestingly, in contrast to previous studies [6, 8, 20,21], time to the shock resolution was not shortened in the steroid group. There are a few plausible explanations for this difference. First, we evaluated only neutropenic patients. Over half of the patients had hematologic malignancies, suggesting that the altered immune systems of these patients may have negatively impacted the results. In fact, the presence of superinfection was more frequent in patients treated with hydrocortisone in our study. In a previous study in which non-neutropenic patients were included, it was reported that superinfection, such as new sepsis or septic shock, occurred more frequently in the steroid group [6], yet resulting episodes of superinfection may have had a greater impact on patients with compromised immune systems. Second, 
Table 1 Clinical characteristics of patients before and after propensity score matching

\begin{tabular}{|c|c|c|c|c|c|c|}
\hline & \multicolumn{3}{|l|}{ Original } & \multicolumn{3}{|c|}{ Propensity-score matched } \\
\hline & No-steroid $(n=189)$ & Steroid $(n=98)$ & $p$ value & No-steroid $(n=50)$ & Steroid $(n=50)$ & $p$ value \\
\hline Age, years, mean $\pm \mathrm{SD}$ & $53.5 \pm 16.0$ & $57.2 \pm 12.3$ & 0.031 & $54.5 \pm 14.9$ & $56.5 \pm 13.5$ & 0.388 \\
\hline Female sex & $68(36.0)$ & $30(30.6)$ & 0.437 & $13(26.0)$ & $12(24.0)$ & $>0.999$ \\
\hline Body mass index, $\mathrm{kg} / \mathrm{m}^{2}$, mean $\pm \mathrm{SD}$ & $22.5 \pm 3.5$ & $22.5 \pm 3.5$ & 0.938 & $22.2 \pm 3.1$ & $22.5 \pm 3.4$ & 0.664 \\
\hline SOFA score & $9.0 \pm 3.0$ & $10.6 \pm 2.9$ & $<0.001$ & $10.0 \pm 3.0$ & $10.1 \pm 2.9$ & 0.865 \\
\hline ICU admission & $89(47.1)$ & $95(96.9)$ & $<0.001$ & $35(70.0)$ & $48(96.0)$ & 0.002 \\
\hline Underlying disease & & & 0.079 & & & 0.412 \\
\hline Acute myeloid/lymphoblastic leukemia & $90(47.6)$ & $36(36.7)$ & & $24(48.0)$ & $18(36.0)$ & \\
\hline Lymphoma & $45(23.8)$ & $19(19.4)$ & & $11(22.0)$ & $10(20.0)$ & \\
\hline Solid malignancy & $35(18.5)$ & $24(24.5)$ & & $10(20.0)$ & $11(22.0)$ & \\
\hline Other hematologic disorders ${ }^{\mathrm{a}}$ & $16(8.5)$ & $14(14.3)$ & & $3(6.0)$ & $9(18.0)$ & \\
\hline No hematologic/oncologic disorders & $3(1.6)$ & $5(5.1)$ & & $2(4.0)$ & $2(4.0)$ & \\
\hline Cause of neutropenia & & & 0.791 & & & 0.750 \\
\hline Chemotherapy & $150(79.4)$ & $74(75.5)$ & & $37(74.0)$ & $36(72.0)$ & \\
\hline Hematologic malignancy & $30(15.9)$ & $17(17.4)$ & & $9(18.0)$ & $11(22.0)$ & \\
\hline Sepsis-induced & $7(3.7)$ & $6(6.1)$ & & $3(6.0)$ & $3(6.0)$ & \\
\hline Drug-induced & $2(1.1)$ & $1(1.0)$ & & $1(2.0)$ & $0(0.0)$ & \\
\hline Cause of septic shock & & & $<0.001$ & & & 0.596 \\
\hline Pneumonia & $42(22.2)$ & $48(49.0)$ & & $19(38.0)$ & $22(44.0)$ & \\
\hline Unknown & $59(31.2)$ & $15(15.3)$ & & $8(16.0)$ & $10(20.0)$ & \\
\hline Bacteremia or fungemia & $56(29.6)$ & $21(21.4)$ & & $15(30.0)$ & $10(20.0)$ & \\
\hline GI origin & $24(12.7)$ & $11(11.2)$ & & $7(14.0)$ & $5(10.0)$ & \\
\hline Others & $8(4.2)$ & $3(3.1)$ & & $1(2.0)$ & $3(6.0)$ & \\
\hline \multicolumn{7}{|l|}{ Vasopressor requirement } \\
\hline Vasopressin & $62(32.8)$ & $90(91.8)$ & $<0.001$ & $42(84.0)$ & $42(84.0)$ & $>0.999$ \\
\hline Epinephrine & $2(1.1)$ & $40(40.8)$ & $<0.001$ & $2(4.0)$ & $2(4.0)$ & $>0.999$ \\
\hline Mechanical ventilation & $45(23.8)$ & $80(81.6)$ & $<0.001$ & $21(42.0)$ & $34(68.0)$ & 0.016 \\
\hline Bacteremia & $95(50.3)$ & $54(55.1)$ & 0.514 & $29(58.0)$ & $20(40.0)$ & 0.124 \\
\hline Duration of neutropenia, days, mean $\pm \mathrm{SD}$ & $12.4 \pm 15.7$ & $8.4 \pm 12.4$ & 0.019 & $11.7 \pm 17.0$ & $8.7 \pm 14.3$ & 0.292 \\
\hline Recovery of neutropenia & $129(68.3)$ & $58(59.2)$ & 0.162 & $28(56.0)$ & $33(66.0)$ & 0.404 \\
\hline
\end{tabular}

Data are presented as numbers $(\%)$ and mean \pm standard deviation

${ }^{a}$ Other hematologic disorders include aplastic anemia, hemophagocytic lymphohistiocytosis, multiple myeloma, myelodysplastic syndrome, progressive myelofibrosis, and leukemia other than acute myeloid leukemia and acute lymphoblastic leukemia

$S O F A$, sequential organ failure assessment; $I C U$, intensive care unit; $G I$, gastrointestinal

Table 2 Study outcomes

\begin{tabular}{|c|c|c|c|c|c|c|}
\hline & \multicolumn{3}{|l|}{ Original } & \multicolumn{3}{|c|}{ Propensity score matched } \\
\hline & $\begin{array}{l}\text { No-steroid } \\
(n=189)\end{array}$ & $\begin{array}{l}\text { Steroid } \\
(n=98)\end{array}$ & $p$ value & $\begin{array}{l}\text { No-steroid } \\
(n=50)\end{array}$ & $\begin{array}{l}\text { Steroid } \\
(n=50)\end{array}$ & $p$ value \\
\hline 28-day mortality & $55(29.1)$ & $47(48.0)$ & 0.002 & $19(38.0)$ & $21(42.0)$ & 0.838 \\
\hline Length of ICU stay, days & $8.8 \pm 13.7$ & $12.6 \pm 14.2$ & 0.066 & $10.9 \pm 17.5$ & $10.0 \pm 12.1$ & 0.639 \\
\hline Length of hospital stay, days & $25.6 \pm 26.2$ & $29.0 \pm 31.6$ & 0.358 & $25.8 \pm 28.4$ & $25.8 \pm 26.6$ & 0.976 \\
\hline Time to the shock resolution, days & $3.0 \pm 3.2$ & $4.9 \pm 4.7$ & 0.001 & $3.4 \pm 3.1$ & $4.6 \pm 5.0$ & 0.110 \\
\hline Length of mechanical ventilation, days & $13.0 \pm 16.2$ & $13.8 \pm 15.0$ & 0.760 & $14.4 \pm 19.4$ & $13.7 \pm 15.8$ & 0.665 \\
\hline
\end{tabular}

Data are presented as numbers $(\%)$ and mean \pm standard deviation

$I C U$, intensive care unit 
Table 3 Adverse events

\begin{tabular}{|c|c|c|c|c|c|c|}
\hline & \multicolumn{3}{|l|}{ Original } & \multicolumn{3}{|c|}{ Propensity score matched } \\
\hline & $\begin{array}{l}\text { No-steroid } \\
(n=189)\end{array}$ & $\begin{array}{l}\text { Steroid } \\
(n=98)\end{array}$ & $p$ value & $\begin{array}{l}\text { No-steroid } \\
(n=50)\end{array}$ & $\begin{array}{l}\text { Steroid } \\
(n=50)\end{array}$ & $p$ value \\
\hline \multicolumn{7}{|l|}{ Superinfection } \\
\hline Pneumonia & $10(5.3)$ & $19(19.4)$ & $<0.001$ & $5(10.0)$ & $9(18.0)$ & 0.289 \\
\hline $\begin{array}{l}\text { Bacteremia or } \\
\text { fungemia }\end{array}$ & $28(14.8)$ & 19 (19.4) & 0.410 & $11(22.0)$ & $11(22.0)$ & $>0.999$ \\
\hline Others $^{\mathrm{a}}$ & $3(1.6)$ & $4(4.1)$ & 0.371 & $1(2.0)$ & $2(4.0)$ & $>0.999$ \\
\hline GI bleeding & $5(2.7)$ & $7(7.1)$ & 0.135 & $0(0.0)$ & $4(8.0)$ & 0.126 \\
\hline
\end{tabular}

Data are presented as numbers $(\%)$

${ }^{a}$ Others included infections of gastrointestinal origin including enterocolitis, chronic disseminated candidiasis, and invasive mucormycosis

GI, gastrointestinal

the positive effects of corticosteroid may not apply to neutropenic patients. Corticosteroids modulate a response to sepsis by inhibiting overwhelming cytokine synthesis and inflammatory reactions [22]. A stress dose of hydrocortisone has been shown to provide protection against excessive production of tissue-toxic materials and preserve phagocytic functions of neutrophils [23]. However, in the absence of neutrophils, corticosteroids may not have displayed as many protective effects in the study patients. Third, the effect of corticosteroid may be minimal in patients receiving high-dose norepinephrine.

The risk of superinfection accompanied by adjunctive corticosteroid use has been reported by few studies [5, 6]. In our study, the steroid group had a significantly higher incidence rate of superimposed pneumonia. Because this study was not a randomized controlled trial, we were not able to assure whether the superimposed pneumonia is attributed to the use of hydrocortisone; therefore, propensity score--matched patients were compared for adverse events. Although not statistically significant, incidence of pneumonia was numerically higher and gastrointestinal bleeding was found only in patients in the steroid group. Even though it is difficult to draw a firm conclusion due to a small number of patients, the findings of our study indicate important aspects that should not be overlooked particularly in patients with compromised immune systems. Secondary pneumonia may lead to a delay in ventilator weaning that can contribute to a higher mortality and morbidity. Moreover, concomitant thrombocytopenia or coagulopathy that can occur in patients with bone marrow dysfunction or those who received myeloablating chemotherapy may lead to a significantly increased risk of bleeding. Therefore, physicians should pay attention to the possible risk of developing secondary infection or bleeding when using corticosteroid in neutropenic patients. Since the present study did not find statistically significant difference, however, further randomized controlled trials regarding this issue are required.

Limitations should be considered to correctly interpret the results of the present study. First, this was a retrospective study conducted at a single center and the results may not be generalized to other patients in different settings. Second, this study was not a randomized controlled trial; thus, there were baseline discrepancies in patient characteristics and disease severity between groups. Hydrocortisone was administered when high-dose norepinephrine or vasopressin was required to maintain an adequate hemodynamic status. Patients with more serious illness might have been included in the analysis although we performed propensity score matching to minimize these baseline differences. Third, do-not-resuscitate orders might have affected the treatment outcomes such as 28-day mortality. However, all patients received the same initial resuscitation management for septic shock and most do-notresuscitate decisions were taken among patients who did not improve despite treatment. Fourth, hyperglycemia and neuromuscular weakness are reported as important adverse events of corticosteroid treatment [24], but their incidence was not investigated in our study. Finally, we did not address the adequacy of antibiotics administration and source control in the study patients.

In conclusion, 28-day mortality was not statistically different between patients treated with and without hydrocortisone. In addition, lengths of ICU and hospital stay, time to the shock resolution, and length of mechanical ventilator treatment did not differ. Since hydrocortisone was used when high-dose norepinephrine or vasopressin is required in our study, further prospective studies for early administration of hydrocortisone may be needed to demonstrate the effect of adjunctive steroid in neutropenic patients with septic shock.

\section{Compliance with ethical standards}

The study protocol was approved by the institutional review board of Asan Medical Center (No. 2018-0206), and the need for informed consent was waived due to the retrospective nature of the study.

Conflict of interest The authors declare that they have no conflict of interest. 


\section{References}

1. Annane D, Bellissant E, Bollaert PE, Briegel J, Confalonieri M, de Gaudio R, Keh D, Kupfer Y, Oppert M, Meduri GU (2009) Corticosteroids in the treatment of severe sepsis and septic shock in adults: a systematic review. Jama 301:2362-2375. https://oi. org/10.1001/jama.2009.815

2. Minneci PC, Deans KJ, Eichacker PQ, Natanson C (2009) The effects of steroids during sepsis depend on dose and severity of illness: an updated meta-analysis. Clin Microbiol Infect 15:308318. https://doi.org/10.1111/j.1469-0691.2009.02752.x

3. Moran JL, Graham PL, Rockliff S, Bersten AD (2010) Updating the evidence for the role of corticosteroids in severe sepsis and septic shock: a Bayesian meta-analytic perspective. Crit Care 14: R134. https://doi.org/10.1186/cc9182

4. Sherwin RL, Garcia AJ, Bilkovski R (2012) Do low-dose corticosteroids improve mortality or shock reversal in patients with septic shock? A systematic review and position statement prepared for the American Academy of Emergency Medicine. J Emerg Med 43:712. https://doi.org/10.1016/j.jemermed.2011.08.015

5. Annane D, Sebille V, Charpentier C et al (2002) Effect of treatment with low doses of hydrocortisone and fludrocortisone on mortality in patients with septic shock. Jama 288:862-871

6. Sprung CL, Annane D, Keh D, Moreno R, Singer M, Freivogel K, Weiss YG, Benbenishty J, Kalenka A, Forst H, Laterre PF, Reinhart K, Cuthbertson BH, Payen D, Briegel J, CORTICUS Study Group (2008) Hydrocortisone therapy for patients with septic shock. N Engl J Med 358:111-124. https://doi.org/10.1056/NEJMoa071366

7. Rhodes A, Evans LE, Alhazzani W, Levy MM, Antonelli M, Ferrer R, Kumar A, Sevransky JE, Sprung CL, Nunnally ME, Rochwerg B, Rubenfeld GD, Angus DC, Annane D, Beale RJ, Bellinghan GJ, Bernard GR, Chiche JD, Coopersmith C, de Backer DP, French CJ, Fujishima S, Gerlach H, Hidalgo JL, Hollenberg SM, Jones AE, Karnad DR, Kleinpell RM, Koh Y, Lisboa TC, Machado FR, Marini JJ, Marshall JC, Mazuski JE, McIntyre LA, McLean AS, Mehta S, Moreno RP, Myburgh J, Navalesi P, Nishida O, Osborn TM, Perner A, Plunkett CM, Ranieri M, Schorr CA, Seckel MA, Seymour CW, Shieh L, Shukri KA, Simpson SQ, Singer M, Thompson BT, Townsend SR, van der Poll T, Vincent JL, Wiersinga WJ, Zimmerman JL, Dellinger RP (2017) Surviving Sepsis Campaign: international guidelines for management of sepsis and septic shock: 2016. Crit Care Med 45:486-552. https://doi. org $/ 10.1097 / \mathrm{ccm} .0000000000002255$

8. Venkatesh B, Finfer S, Cohen J, Rajbhandari D, Arabi Y, Bellomo R, Billot L, Correa M, Glass P, Harward M, Joyce C, Li Q, McArthur C, Perner A, Rhodes A, Thompson K, Webb S, Myburgh J (2018) Adjunctive glucocorticoid therapy in patients with septic shock. N Engl J Med 378:797-808. https://doi.org/10. 1056/NEJMoa1705835

9. Annane D, Renault A, Brun-Buisson C, Megarbane B, Quenot JP, Siami S, Cariou A, Forceville X, Schwebel C, Martin C, Timsit JF, Misset B, Ali Benali M, Colin G, Souweine B, Asehnoune K, Mercier E, Chimot L, Charpentier C, François B, Boulain T, Petitpas F, Constantin JM, Dhonneur G, Baudin F, Combes A, Bohé J, Loriferne JF, Amathieu R, Cook F, Slama M, Leroy O, Capellier G, Dargent A, Hissem T, Maxime V, Bellissant E (2018) Hydrocortisone plus fludrocortisone for adults with septic shock. N Engl J Med 378:809-818. https://doi.org/10.1056/ NEJMoa1705716
10. Bodey GP, Buckley M, Sathe YS, Freireich EJ (1966) Quantitative relationships between circulating leukocytes and infection in patients with acute leukemia. Ann Intern Med 64:328-340

11. Legrand M, Max A, Peigne V, Mariotte E, Canet E, Debrumetz A, Lemiale V, Seguin A, Darmon M, Schlemmer B, Azoulay É (2012) Survival in neutropenic patients with severe sepsis or septic shock. Crit Care Med 40:43-49. https://doi.org/10.1097/CCM. 0b013e31822b50c2

12. Vincent JL, Moreno R, Takala J et al (1996) The SOFA (Sepsisrelated organ failure assessment) score to describe organ dysfunction/failure. On behalf of the working group on sepsis-related problems of the European Society of Intensive Care Medicine. Intensive Care Med 22:707-710

13. Singer M, Deutschman CS, Seymour CW, Shankar-Hari M, Annane D, Bauer M, Bellomo R, Bernard GR, Chiche JD, Coopersmith CM, Hotchkiss RS, Levy MM, Marshall JC, Martin GS, Opal SM, Rubenfeld GD, van der Poll T, Vincent JL, Angus DC (2016) The third international consensus definitions for sepsis and septic shock (Sepsis-3). Jama 315:801-810. https://doi.org/10. 1001/jama.2016.0287

14. Dellinger RP, Levy MM, Rhodes A, Annane D, Gerlach H, Opal SM, Sevransky JE, Sprung CL, Douglas IS, Jaeschke R, Osborn TM, Nunnally ME, Townsend SR, Reinhart K, Kleinpell RM, Angus DC, Deutschman CS, Machado FR, Rubenfeld GD, Webb SA, Beale RJ, Vincent JL, Moreno R (2013) Surviving sepsis campaign: international guidelines for management of severe sepsis and septic shock: 2012. Crit Care Med 41:580-637. https://doi.org/10.1097/CCM. 0b013e31827e83af

15. Dellinger RP, Levy MM, Carlet JM, Bion J, Parker MM, Jaeschke R, Reinhart K, Angus DC, Brun-Buisson C, Beale R, Calandra T, Dhainaut JF, Gerlach H, Harvey M, Marini JJ, Marshall J, Ranieri M, Ramsay G, Sevransky J, Thompson BT, Townsend S, Vender JS, Zimmerman JL, Vincent JL (2008) Surviving Sepsis Campaign: international guidelines for management of severe sepsis and septic shock: 2008. Crit Care Med 36:296-327. https://doi.org/10.1097/01.Ccm. 0000298158.12101 .41

16. Nauseef WM, Borregaard N (2014) Neutrophils at work. Nat Immunol 15:602-611. https://doi.org/10.1038/ni.2921

17. Kalil AC, Opal SM (2015) Sepsis in the severely immunocompromised patient. Curr Infect Dis Rep 17(487). https://doi.org/10.1007/ s11908-015-0487-4

18. Annane D, Cariou A, Maxime V et al (2010) Corticosteroid treatment and intensive insulin therapy for septic shock in adults: a randomized controlled trial. Jama 303:341-348. https://doi.org/10. 1001/jama.2010.2

19. Polito A, Hamitouche N, Ribot M, Polito A, Laviolle B, Bellissant E, Annane D, Alvarez JC (2016) Pharmacokinetics of oral fludrocortisone in septic shock. Br J Clin Pharmacol 82:15091516. https://doi.org/10.1111/bcp.13065

20. Annane D (2005) Glucocorticoids in the treatment of severe sepsis and septic shock. Curr Opin Crit Care 11:449-453

21. Oppert M, Schindler R, Husung C, Offermann K, Gräf KJ, Boenisch O, Barckow D, Frei U, Eckardt KU (2005) Low-dose hydrocortisone improves shock reversal and reduces cytokine levels in early hyperdynamic septic shock. Crit Care Med 33: 2457-2464

22. Keh D, Boehnke T, Weber-Cartens S, Schulz C, Ahlers O, Bercker S, Volk HD, Doecke WD, Falke KJ, Gerlach H (2003) Immunologic and hemodynamic effects of "low-dose" 
hydrocortisone in septic shock: a double-blind, randomized, placebo-controlled, crossover study. Am J Respir Crit Care Med 167: 512-520. https://doi.org/10.1164/rccm.200205-446OC

23. Kaufmann I, Briegel J, Schliephake F, Hoelzl A, Chouker A, Hummel T, Schelling G, Thiel M (2008) Stress doses of hydrocortisone in septic shock: beneficial effects on opsonization-dependent neutrophil functions. Intensive Care Med 34:344-349. https://doi. org/10.1007/s00134-007-0868-8
24. Patel GP, Balk RA (2012) Systemic steroids in severe sepsis and septic shock. Am J Respir Crit Care Med 185:133-139. https://doi. org/10.1164/rccm.201011-1897CI

Publisher's note Springer Nature remains neutral with regard to jurisdictional claims in published maps and institutional affiliations. 